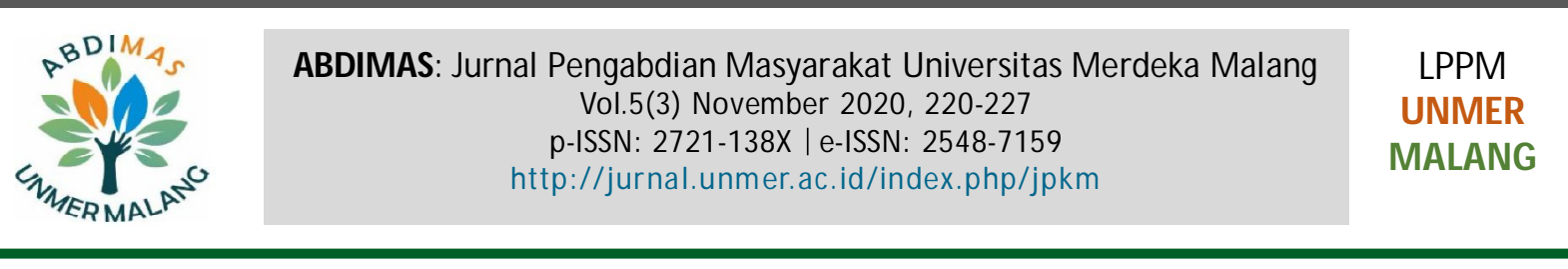

\title{
Pelatihan Melukis One Stroke Painting bagi Kelompok Masyarakat Gondowangi Malang
}

\author{
Sultan Arif Rahmadianto', Yuyun Yuniati ${ }^{2}$ \\ ${ }^{1}$ Departemen Desain Komunikasi Visual, ${ }^{2}$ Departemen Kimia, Fakultas Sains dan Teknologi, Universitas Ma Chung \\ Jl. Villa Puncak Tidar No.1, Malang, 65151, Indonesia
}

ARTICLE INFO:

Received: 2020-05-29

Revised: 2020-07-04

Accepted: 2020-09-11

\section{Keywords:}

Art creations; Corporate social responsibility program; Gondowangi; One stroke painting

\section{ABSTRACT}

The people of Gondowangi, Malang need a program to improve knowledge and skills art creations. One stroke painting is a simple painting technique that can produce unique and interesting visual works despite using only very simple techniques. Based on situation analysis, Ma Chung University created a corporate social responsibility program (CSR) aimed at empowering the people of Gondowangi, Malang in terms of knowledge and skills art creations. This program will be able to have a great influence on the people of Gondowangi, Malang, which is to make more productive and able to produce art products that have economic value. The method of this program is the first day is a socialization activity about the knowledge of painting with one stroke painting technique, then day two is a direct training activity painting with one stroke painting technique. The people are very enthusiastic to participate in this program. As a result of this program, the people of Gondowangi, Malang are more confident in painting and have art products. The sustainability of this program is excellent because has a consultation program that is coordinated directly between the head of this program and the head of people Gondowangi, Malang to ensure better cooperation in the future.

(C) 2020 Published by University of Merdeka Malang. This is an open access article distributed under the CC BY-SA 4.0 license (https://creativecommons.org/licenses/by-sa/4.0/)

How to cite: Rahmadianto, S. A. (2020). Pelatihan Melukis One Stroke Painting bagi Kelompok Masyarakat Gondowangi Malang. Abdimas: Jurnal Pengabdian Masyarakat Universitas Merdeka Malang, 5(2), 220-227.

https://doi.org/10.26905/abdimas.v5i2.4241

\section{Pendahuluan}

Salah satu kebutuhan primer manusia adalah sebuah permukiman, agar manusia dapat hidup layak dan sejahtera sesuai dengan status kemanusiaannya. Kebutuhan ini sebenarnya adalah sebuah kebutuhan perorangan namun bisa berkembang menjadi kebutuhan kelompok ketika manusia berkeluarga dan bermasyarakat. Manusia merupakan makhluk sosial yang tidak bisa hidup sendiri-sendiri akan tetapi hidup bersama dan membentuk kelompok-kelompok. Permukiman (settlement) adalah rumah tempat tinggal dibangun secara bersama-sama dan tersebar dalam suatu wilayah lengkap dengan sarana dan prasarana yang diperlukan penghuninya (Banowati, 2006). 


\section{Pelatihan Melukis One Stroke Painting Bagi Kelompok Masyarakat Gondowangi Malang}

Sultan Arif Rahmadianto, Yuyun Yuniati

Sebuah permukiman dapat berkembang dengan sangat baik dipengaruhi oleh penghuni permukiman itu sendiri (Tutuko dkk., 2018). Desa Gondowangi adalah suatu permukiman yang berada di Kabupaten Malang Provinsi Jawa Timur. Desa ini memiliki potensi yang bisa dikembangkan lebih lanjut seperti dibidang pertanian, peternakan, dan budaya. Peningkatan potensi ini sangat penting bagi pekembangan suatu desa (Indawati dkk., 2018). Bapak Danis selaku Kepala Desa Gondowangi dikenal sebagai sosok yang ingin mengabdikan dirinya sepenuhnya untuk kemajuan desa Gondowangi. Salah satu program yang dijalankan untuk menunjang kemajuan desa adalah menghidupkan dan menggerakkan generasi muda untuk bisa lebih produktif dan kreatif melalui organisasi Pencinta Alam yaitu Anak Muda Pencinta Alam Semesta (Ampas) (Henky, 2014). Danis mengharapkan masyarakat atau pemuda di desa Gondowangi tidak perlu susah payah bekerja di daerah lain dan cukup bekerja di desanya saja. Sehingga untuk mewujudkan itu semua terdapat banyak program yang dijalankan seperti progam pemberdayaan ibu dan anak, program kepemudaan, dimana program ini menciptakan ladang bisnis berbasis masyarakat berdasarkan potensi yang dimiliki desa Gondowangi. Selain itu, Kepala Desa Danis juga bakal mengundang investor ke desanya untuk penguatan modal bisnis. Pengembangan ekonomi lainnya juga senantiasa diperhatikan untuk menciptakan kondisi yang lebih baik untuk pertumbuhan ekonomi dan penciptaan lapangan kerja di tingkat lokal desa Gondowangi, Malang (Azizah, 2015).

Potensi budaya dan kesenian desa Gondowangi terbukti mencuri perhatian masyarakat luar sampai mancanegara. Masyarakat Gondowangi dikenal memiliki berbagai kreativitas dalam menciptakan kreasi kesenian dalam pagelaran, semisal Festival Kampung Dilem yang kekinian (Nana, 2018).

Namun, potensi yang luar biasa ini belum sepenuhnya maksimal karena minimnya kolaborasi dari elemen masyarakat lainnya. Salah satunya adalah dari sisi perguruan tinggi, untuk itu perlu adanya sebuah sinergi antara lingkungan akademis perguruan tinggi dengan kelompok masyarakat Gondowangi lewat program tahunan pengabdian bagi masyarakat yang dimiliki oleh lingkungan perguruan tinggi untuk bisa memaksimalkan berbagai potensi yang dimiliki, dalam hal ini yang bisa ditingkatkan adalah dalam hal seni (Rokhmah \& Anggorowati, 2017).

Berdasarkan analisis situasi yang telah dilakukan oleh tim pengabdian bagi masyarakat ditemukan kebutuhan masyarakat Gondowangi terhadap pelatihan melukis. Melukis adalah kegiatan yang menggembirakan. M elalui aktivitas ini seseorang mampu mengekspresikan kreativitasnya. Selain itu, melukis juga tidak membutuhkan biaya yang mahal. Hanya dengan pensil dan selembar kertas seseorang bisa menghasilkan suatu karya dari melukis. Dikarenakan melukis merupakan kegiatan yang mudah untuk dilakukan, sehingga banyak orang yang mengalokasikan waktunya untuk melukis. Selain itu, menurut Ana (2015) kegiatan melukis memiliki beberapa manfaat, sebagai berikut:

Melukis melatih seseorang untuk terlatih berkomunikasi secara berbeda melalui bahasa personal. Hal ini bisa membantu seseorang yang memiliki permasalahan dalam berkomunikasi ataupun dalam mengekspresikan diri sendiri, seperti autisme, disabilitas, dan lainnya.

Melukis merupakan kegiatan individu yang bisa dilaksanakan baik itu di dalam ruangan atau di luar sekalipun. Melalui kegiatan ini seseorang bisa membuat dunia sesuai dengan apa yang diharapkan dimana semua bisa terjadi. Stimulus dari otak kreatif akan mengantarkan seseorang ke sebuah tempat yang positif di luar dunia sebenarnya, yang memberikan kesejukan, menumbuhkan perasaan rileks, dan sebagainya. Hal ini dikhususkan bagi orang-orang yang mengalami kondisi kegelisahan dan agresi.

Sebagian banyak orang mengatakan bahwa melukis bisa menghilangkan stress. Tekanan dalam kehidupan bisa membuat seseorang lelah. Melukis bisa membuat seseorang merasa nyaman. Dengan 
ABDIMAS: Jurnal Pengabdian Masyarakat Universitas Merdeka Malang

Volume 5, No 3, November 2020: 220-227

melukis stress tersebut bisa dikonversi menjadi bentuk warna dan gambar. Menurunnya stress bisa mengurangi risiko penyakit psikis.

Belajar memegang pensil atau kuas bisa membantu seseorang dalam mengelola gerakan tangan, serta menstimulasi hubungan otak di waktu yang bersamaan, sehingga bisa memperkuat kemampuan koordinasi. Melukis juga membantu seorang yang telah lanjut usia dalam meningkatkan kemampuan motorik.

Emosi adalah bagian dari dunia kreatif yang seseorang miliki. Dengan melukis seseorang bisa mengalirkan emosi, sehingga menolong untuk menghasilkan keselarasan antara hati dan pikiran yang akan membawa seseorang pada perasaan senang, cinta, empati dan kedamaian. Pada kondisi yang sedang kurang baik, visualisasi dan relaksasi yang diperoleh dari melukis adalah suatu alat untuk mengatur energi, emosional, dan kehidupan spiritual.

\section{Meningkatkan kepercayaan diri}

Melihat hasil kerja keras yang baik, dapat membuat seseorang menjadi bahagia dan merasa lebih nyaman dalam menyelesaikan sebuah lukisan. Sehingga, dapat menstimulasi rasa kepercayaan diri seseorang. Mendapatkan tanggapan yang baik dari banyak orang yang menyaksikan lukisan tersebut juga bisa meningkatkan rasa kepercayaan diri seseorang.

M elukis berguna bagi kesehatan yaitu mampu meningkatkan kemampuan mengingat atau memanggil kembali ingatan. Dengan melukis kemampuan otak dilatih untuk meningkatkan ketajaman dalam berimajinasi dan berpikir.

\section{Meningkatkan kreativitas}

M elukis memanfaatkan imajinasi seperti ketika membuat suatu pemandangan, orang-orang, maupun bentuk lainnya. Seseorang bisa melukiskan emosi dan menciptakan gambar abstrak sebagai outputnya. Sehingga meningkatkan kemampuan artistik yang ada pada otak kanan seseorang. Selain itu, otak sebelah kiri yang biasanya dominan pada kemampuan analisis, dapat juga terstimulasi untuk menghasilkan kreativitas.

Melukis sangat disarankan untuk anak-anak. Hal ini dikarenakan banyak ana-anak yang sedang mengalami perkembangan di umurnya lebih banyak memilih kegiatan melukis. Melukis bisa membantu mengembangkan kemampuan otak mereka, mereka akan lebih siap dalam menyelesaikan tugas akademik. Kemudian tidak hanya itu, mereka dapat lebih mudah dalam mendapatkan teman karena melukis akan ada kegiatan sharing dengan teman-temannya.

Kemampuan berpikir kritis dan memecahkan masalah bisa meningkat dengan melukis. Melukis memungkinkan seseorang untuk menyadari bahwa terdapat banyak solusi untuk menyelesaikan satu permasalahan. Ketika seseorang menghasilkan suatu karya, maka akan dilatih untuk mengembangkan suatu teknik dimana mengubah kertas putih menjadi suatu karya serta melatih untuk berpikir yang out of the box.

Observasi pada properti lukisan pada lingkungan sekitar seperti pewarnaan, sading, dan lainnya melatih seseorang dalam meningkatkan kemampuan observasi. Indra visual terlatih untuk menyelesaikan sesuatu yang rumit pada sebuah goresan lukisan. Sehingga hal ini bisa meningkatkan konsentrasi otak 


\section{Pelatihan Melukis One Stroke Painting Bagi Kelompok Masyarakat Gondowangi Malang}

Sultan Arif Rahmadianto, Yuyun Yuniati

seseorang. Dengan demikian, kemampuan observasi juga akan meningkat seiring terbiasanya seseorang untuk melukis.

Melukis juga bisa menjadi suatu kegiatan yang konvensional. Banyak orang yang memiliki hobi melukis kemudian menjadikannya sebagai mata pencaharian maupun penghasilan tambahan.

Banyak manfaat yang bisa didapat ketika kegiatan ini bisa disosialisasikan pada masyarakat sehingga tim pengabdian melakukan sosialisasi serta pelatihan melukis dengan menggunakan teknik one stroke painting. One stroke painting adalah suatu teknik melukis dekoratif yang popular dan dikembangkan oleh seniman Donna Dewberry, dimana menggunakan satu kuas dengan memanfaatkan dua sisi mata kuas untuk diisi warna berbeda yaitu highlights dan shadows sehingga menghasilkan visual yang unik dan menarik ketika digoreskan pada kanvas atau media lukis lainnya (Grouse, 2018).
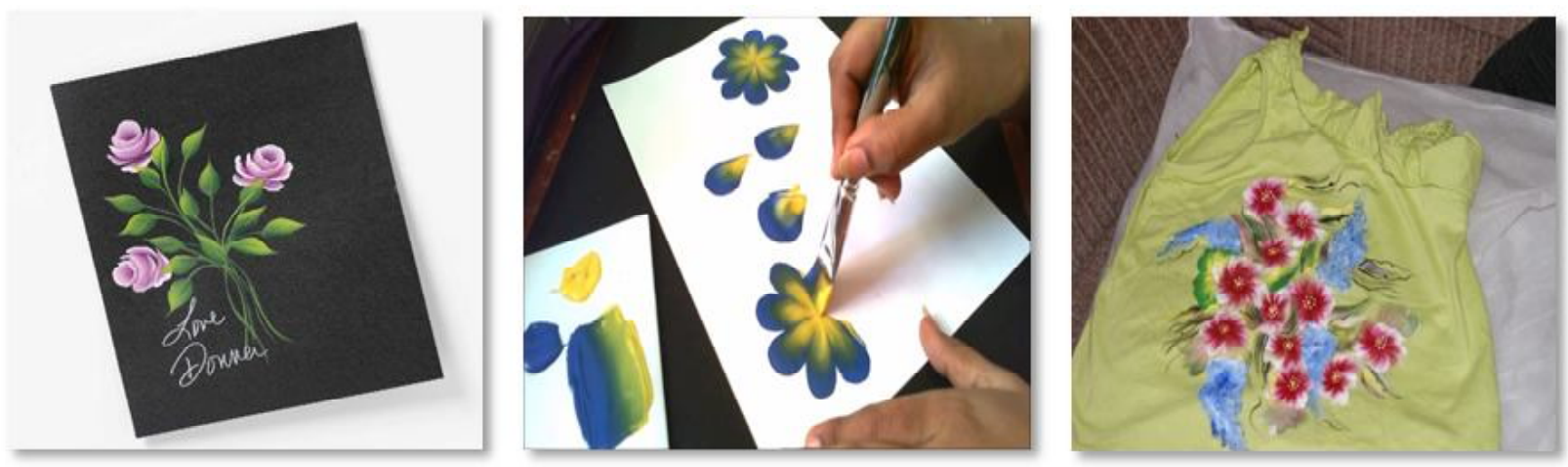

Gambar 2. Karya seni menggunakan teknik one stroke painting

Gambar 3. Teknik dasar onestroke painting

Gambar 4. Aplikasi one stroke painting pada media kain

Teknik one stroke painting tidak membutuhkan kemampuan khusus dari peserta pelatihan sehingga pelatihan ini bisa diikuti oleh berbagai usia tanpa memperhatikan kemampuan khusus dalam melukis (Dewberry, 2019). Kemudahan dari teknik ini menawarkan berbagai manfaat untuk jangka panjang seperti membuka peluang usaha baru bagi peserta pelatihan melukis sebagai contoh untuk variasi motif seni pada jilbab, dompet, tas, sepatu dll. Berikut ini Gambar 3 menggambarkan teknik dasar dari one stroke painting.

Tujuan program pengabdian ini adalah untuk memberdayakan kelompok masyarakat Gondowangi, Malang dari sisi ketrampilan yang nantinya akan diberikan suatu pengetahuan dan pelatihan melalui program pengabdian masyarakat sehingga menciptakan kesempatan baru bagi masyarakat untuk lebih produktif dan kreatif dalam menciptakan sesuatu yang memiliki nilai estetis dan diharapkan juga memiliki nilai ekonomi. Teknik one stroke painting dipilih sebagai program pelatihan ini karena memiliki banyak kelebihan yaitu mampu menghasilkan karya visual unik dan menarik sehingga berpotensi menjadi produk UKM yang memiliki nilai ekonomi.

Desa Gondowangi juga telah memiliki BUMDes yang bertujuan sebagai badan usaha untuk kesejahteraan warga (Hapsari, 2016). Oleh karena itu ketika kedepannya kelompok masyarakat Gondowangi memiliki produk UKM yang baik dan marketable bisa bekerja sama dan melakukan kolaborasi dengan 
ABDIMAS: Jurnal Pengabdian Masyarakat Universitas Merdeka Malang Volume 5, No 3, November 2020: 220-227

BUM Des. Peran program pengabdian bagi masyarakat selain melalukan transfer IPTEK juga berusaha mendorong dan memberdayakan masyarakat untuk mampu mengatasi permasalahan yang ada dilingkungannya tersebut.

\section{Metode}

Kegiatan pelatihan melukis dengan teknik one stroke painting bagi kelompok masyarakat Gondowangi memiliki pendekatan kualitatif deskriptif dengan konsep program pengabdian masyarakat, diawali dengan dilaksanakan sosialisasi tentang melukis dengan menggunakan teknik one stroke painting, kemudian dilanjutkan dengan pelatihan one stroke painting (Lexy, 2007).

Program pengabdian ini bertujuan untuk memaksimalkan kemampuan kelompok masyarakat dalam mempraktekkan teknik one stroke painting yang telah diajarkan untuk bisa menciptakan karya visual unik dan menarik sehingga berpotensi menjadi produk UKM yang memiliki nilai ekonomi. Pelatihan melukis ini melibatkan langsung seluruh tim pengabdian dan juga mengundang satu narasumber Bapak Habiby Rahmadianto, S.Pd yang memiliki kompetensi di bidang seni rupa. Narasumber ini diperlukan untuk suplemen kegiatan agar lebih berkualitas dalam memperkaya wawasan dan teknik one stroke painting yang bisa disampaikan pada kelompok Masyarakat Gondowangi. Desain program pengabdian bagi masyarakat pelatihan one stroke painting: (1) Sosialisasi tentang melukis menggunakan teknik one stroke painting; (2) Pelatihan oleh narasumber dan tim abdimas Universitas Ma Chung; (3) Penutupan kegiatan pelatihan melukis one stroke painting.

\section{Hasil dan Pembahasan}

Pelaksanaan kegiatan sosialisasi tentang melukis dengan menggunakan teknik one stroke painting ini diawali sambutan dari tim pengabdian masyarakat yang diwakili oleh Bapak Sultan Arif Rahmadianto, S.Sn., M.Ds. dengan konten tentang peluang industri kreatif dan kewirausahaan melalui bidang seni rupa untuk memaksimalkan ekonomi masyarakat Gondowangi. Kegiatan ini dilaksanakan di pendopo kelurahan Gondowangi pukul 19:00 WIB - selesai, pembukaan berjalan dengan lancar diikuti oleh semua peserta dan tim abdimas lihat Gambar 5.
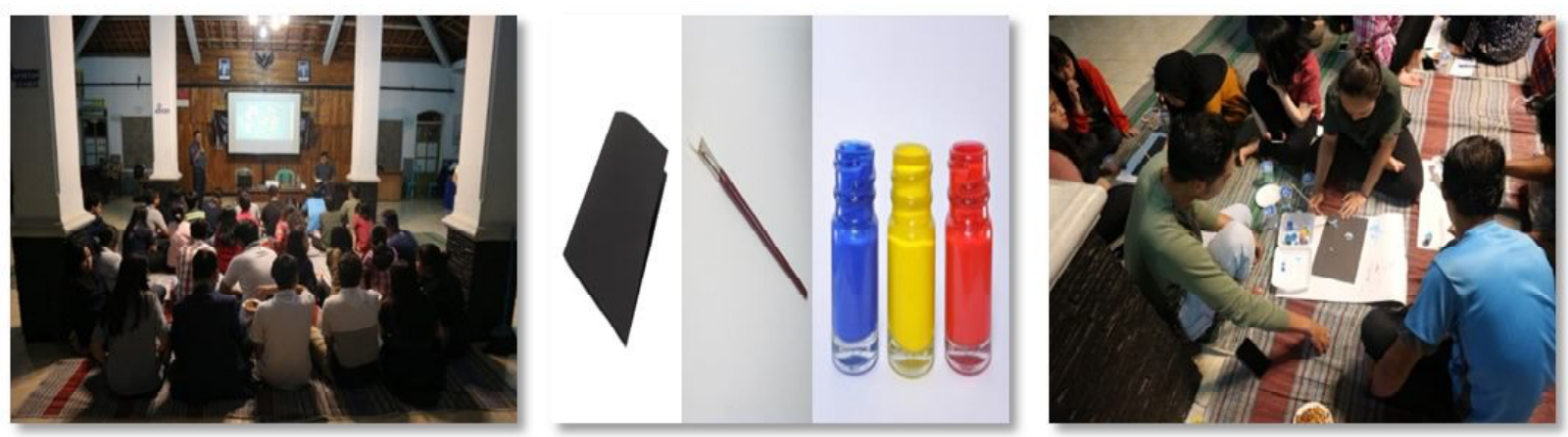

Gambar 5. Pembukaan pelaksanaan sosialisasi melukis one stroke painting

Gambar 6. Peralatan dan bahan melukis one stroke painting

Gambar 7. Aktivitas masing-masing kelompok pelatihan melukis one stroke painting 
Setelah acara pembukaan selesai kegiatan dilanjut dengan sosialisasi pengetahuan tentang melukis dengan menggunakan teknik one stroke painting. Terlihat antusias yang luar biasa dalam mengikuti program pengabdian dari seluruh peserta yang hadir. Narasumber mengawali sesi dengan memberikan ceramah singkat tentang wawasan terkait peralatan dan bahan yang dibutuhkan dalam praktik melukis one stroke painting. Peralatan dan bahan itu terdiri dari (1) kertas linen warna hitam (2) satu buah kuas dan (3) tiga warna primer seperti ditunjukkan pada Gambar 6.

Setelah narasumber menjelaskan tentang peralatan yang dibutuhkan maka selanjutnya tiba waktunya narasumber menjelaskan tentang bagaimana menggunakan peralatan dan bahan yang telah disediakan oleh tim abdimas untuk menghasilkan sebuah karya seni dengan menggunakan teknik one stroke painting. Narasumber menggunakan media bantuan berupa pemutaran video tentang teknik one stroke painting dan tim abdimas mendampingi para peserta untuk memastikan peserta memahami teknik yang diajarkan. Kemudian untuk kemudahan dalam pengenalan melukis ini tim abdimas membagi peserta ke dalam beberapa kelompok dan masing-masing kelompok memiliki ketua sebagai koordinator kelompok lihat Gambar 7.

Kegiatan sosialisasi melukis one stroke painting berjalan dengan lancar dan diikuti oleh seluruh peserta yang hadir. Dari kegiatan ini menghasilkan karya-karya seni yang unik dan menarik yang dihasilkan oleh seluruh peserta yaitu warga Gondowangi seperti pada Gambar 8. Diakhir kegiatan ketua abdimas yaitu Ibu Dr. Yuyun yuniati, ST, MT menyampaikan bahwa kegiatan lanjutan akan terus berjalan yaitu pelatihan pada warga Gondowangi terkait kemampuan dalam melukis menggunakan teknik one stroke painting.
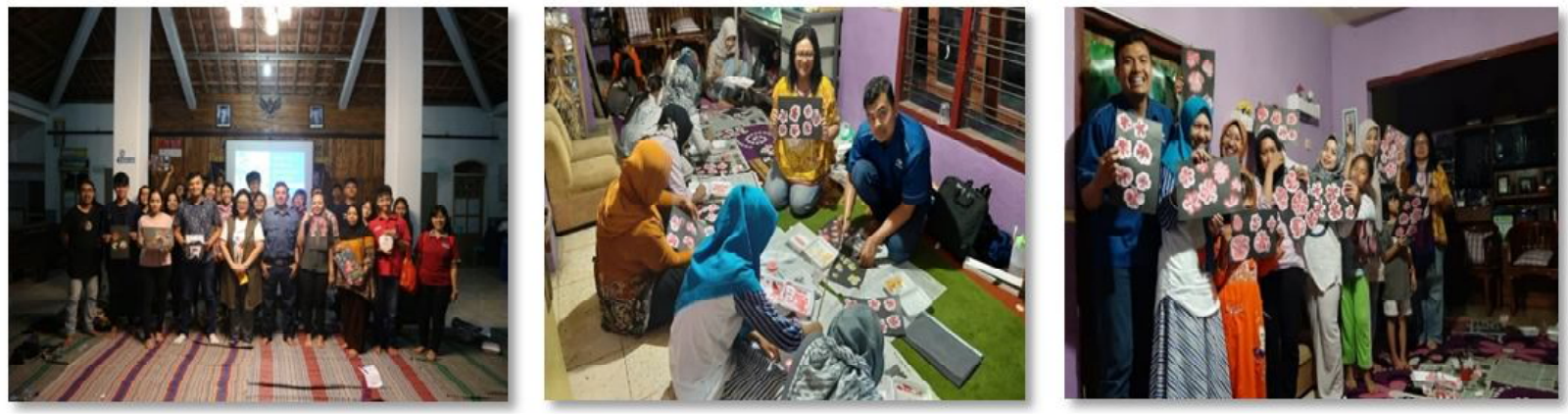

Gambar 8. Photo bersama pada akhir sesi

Gambar 9. Pelatihan intensif melukis one stroke painting

Gambar 10. Hasil pelatihan intensif melukis one stroke painting

Setelah kegiatan sosialisasi telah selesai dilaksanakan dikegiatan selanjutnya adalah penyelenggaraan kegiatan pelatihan yang lebih intensif tentang one stroke painting. Bertujuan untuk memaksimalkan kemampuan kelompok masyarakat dalam mempraktekkan teknik one stroke painting yang telah diajarkan untuk bisa menciptakan karya visual unik dan menarik sehingga berpotensi menjadi produk UKM yang memiliki nilai ekonomi. Pada kegiatan lanjutan ini peserta lebih difokuskan pada kelompok ibu-ibu yang memiliki ketertarikan dan keinginan untuk belajar melukis. Perbedaan dengan kegiatan yang pertama, peserta masih didominasi oleh semua kalangan termasuk karang taruna, dan yang kedua ini didominasi oleh kelompok ibu-ibu warga Gondowangi.

Pada program pelatihan ini peran tim abdimas dalam melaksanakan kegiatan lebih intensif dan dengan seksama memastikan semua peserta yang hadir dan berpartisipasi bisa praktik melukis dengan 
ABDIMAS: Jurnal Pengabdian Masyarakat Universitas Merdeka Malang

Volume 5, No 3, November 2020: 220-227

teknik one stroke painting secara langsung dan mandiri. Hasilnya diluar dugaan semua peserta bisa mengikuti kegiatan dan menciptakan karya seni yang indah dan menarik. Antusias ini terlihat dari banyaknya kertas yang digunakan peserta dalam latihan untuk mengukur kemampuan dari masing masing lihat Gambar 9. Terhitung masing masing peserta sampai menghabiskan 5 sampai 10 kertas.

Hasil dari pelatihan tahap kedua ini lebih maksimal terlihat dari masing-masing peserta telah berhasil menghasilkan karya seni lukisan dengan teknik one stroke painting yang baik lihat Gambar 10. Kemudian ada beberapa peserta juga yang telah eksplorasi dengan media yang berbeda selain kertas linen yaitu di media kain.

Selanjutnya untuk menjaga kualitas program abdimas ini akan dilanjutkan dengan kunjungan 1-2 kali yang bertujuan untuk mengevaluasi pekerjaan melukis dari kelompok yang telah didampingi. Secara kegiatan umum, program sudah selesai, namun tim pelaksana perlu mendapatkan data dampak pelatihan ini melalui evaluasi dengan kelompok dan koordinator Pemberdayaan Masyarakat Desa Gondowangi.

Penutupan dari kegiatan ini berjalan dengan lancar. Terdapat beberapa kesan dan pesan terhadap kegiatan ini yaitu program pengabdian ini agar bisa terus secara kontinu dilakukan di desa Gondowangi karena masyarakat sangat antusias dan memperoleh manfaat yang banyak baik dari segi ketrampilan dan peluang ke arah peningkatan ekonomi masyarakat desa Gondowangi.

\section{SIMPULAN DAN SARAN}

\section{Simpulan}

Dari kegiatan pelatihan ini bisa ditarik kesimpulan metode dalam pelaksanaan sudah efektif dan bisa berjalan dengan baik tergambar bahwa antusias warga Gondowangi sangat tinggi dalam mengikuti program pengabdian. Hal ini dibuktikan dengan keseriusan warga untuk mengikuti proses pelatihan dari awal sampai akhir dan berhasil menghasilkan karya-karya unik dan menarik sehingga berpotensi menjadi produk UKM yang memiliki nilai ekonomi. Program ini sudah bisa menjawab permasalahan yang dihadapi oleh masyarakat Gondowangi, Malang yang membutuhkan pelatihan melukis yang praktis dan bermanfaat. Keberlanjutan dari kegiatan ini juga cukup baik karena tim abdimas juga memiliki sistem konsultasi yang dikoordinasi antara ketua pengabdian dan perwakilan warga. Hambatan yang ditemui dalam kegiatan ini adalah hambatan minor ketika proses pengumpulan warga ke pendopo kelurahan Gondowangi yang sedikit molor.

\section{Saran}

Saran untuk program pengabdian masyarakat selanjutnya adalah masyarakat Gondowangi, Malang membutuhkan pelatihan kreasi seni lainnya yang tujuannya bisa memberikan wawasan dan pengetahuan baru tentang berbagai kreasi seni yang menarik semisal seperti pelatihan membatik (Dwipasari \& Subianto, 2017), diharapkan pula dari pelatihan ini bisa menghasilkan batik khas dari Gondowangi, Malang.

\section{Ucapan Terima Kasih}

Tim pengabdi mengucapkan terima kasih atas kesempatan yang diberikan oleh Universitas $\mathrm{Ma}$ Chung melalui pemberian dana dalam Skema Ma Chung Abdimas Grant (MAG) dengan kontrak Nomor 033/MACHUNG/LPPM - MAG-IbM/III/2019. 


\section{DAFTAR PUSTAKA}

Ana, C. (2015). 11 M anfaat melukis sebagai ho bi menyenangkan. https://manfaat.co.id/manfaat-melukis. (Diakses tanggal 19 Desember 2019).

Azizah, R. (2017). Peran Badan Usaha Milik Desa (Bumdes) dalam peningkatan akses usaha masyarakat di Desa Putukrejo Kecamatan Gondanglegi dan Desa Gondowangi Kecamatan Wagir Kabupaten Malang. Jurnal Ilmiah Mahasiswa FEB, 5(2).

Banowati, E. (2006). Geografi Permukiman. Universitas Negeri Semarang. Semarang.

Dewberry, D. (2019). Complete Book of One Stroke Painting. Craft Decorative. US.

Dwipasari, L., \& Subianto, T. (2017). Pendampingan pengembangan KUB (Kelompok Usaha Bersama) Batik Malangan di Kota Malang. Abdimas: Jurnal Pengabdian Masyarakat Universitas Merdeka Malang, 2(2), 42-50. https://doi.org/10.26905/abdimas.v2i2.1816

Grouse, E. (2018). What is the "One stroke" painting technique?. https://www.evygrouse.com/what-is-the-one-stroke-painting-technique/. (Diakses tanggal 27 September 2019).

Hapsari, D. A. A. (2016). Desa Gondowangi segera miliki BUMDes. https://malangvoice.com/desa-gondowangi-segera-miliki-bumdes/. (Diakses tanggal 27 September 2019).

Henky. (2014). Kades Gondowangi; “Jadi pemimpin adalah amanah yang harus dijalankan”. http:// artinews.blogspot.co m/2014/02/kades-go ndowangi-jadi-pemimpin-adalah.html. (Diakses tanggal 12 Desember 2019).

Indawati, N., Sarwoko, E., \& Wardani, N. R. (2018). Peningkatan produktivitas Biting, Dupa, Dan Sayur Organik Di Kecamatan Wagir Kabupaten Malang. JAPI (Jurnal Akses Pengabdian Indonesia), 3(1), 48-53.

Lexy, M. J. (2007). Metode Penelitian Kualitatif. Remaja Rosda Karya. Bandung.

Nana, D. (2018). Gondowangi potensial dongkrak desa pariwisata, pegiat seni ini berharap Pemkab Malang bersinergi. http://www.malangtimes.com/baca/31019/20180905/193100/gondowangipotensial-dongkrak-desa-pariwisata-pegiat-seni-ini-berharap-pemkab-malang-bersinergi. (Diakses tanggal 27 September 2019).

Rokhmah, N. A., \& Anggorowati, A. (2017). Komunikasi efektif dalam praktek kolaborasi interprofesi sebagai upaya meningkatkan kualitas pelayanan. Journal of Health Studies, 1(1), 65-71. https://doi.org/10.31101/jhes.186

Tutuko, P., Widiyaningtyas, T., Sonalitha, E., \& Nurdewanto, B. (2018). Pemberdayaan kelompok rumah pangan lestari dalam budidaya tanaman hidroponik. JAPI (Jurnal Akses Pengabdian Indonesia), 3(1), 7-16. https://doi.org/10.33366/japi.v3i1.843 